\title{
Failure Mechanism of Pure Epoxy Coating in Near-Neutral Solution Focusing on Coating/Metal Interfaces
}

\author{
Chao Yang ${ }^{1,2, *}$, Guanjun Wang ${ }^{2}$, Qing Han ${ }^{2}$, Haibo Liu $^{2}$, Anquan Wang ${ }^{2}$, Liang Sun ${ }^{2}$ \\ ${ }^{1}$ Postdoctoral Scientific Research Workstation of Shengli Oilfield Company, Dongying, 257000, \\ China; \\ ${ }^{2}$ Technology Inspection Center of Shengli Oilfield, SINOPEC, Dongying, 257000, China \\ "E-mail: yangchao201001@163.com
}

doi: $10.20964 / 2021.03 .67$

Received: 30 September 2020 / Accepted: 24 December 2020 / Published: 31 January 2021

\begin{abstract}
Electrochemical impedance spectroscopy (EIS) can provide a rapid and convenient method for evaluating the coatings' anti-corrosion performance, especially for analyzing the evolution of water diffusion. However, due to the coating/metal interfaces' limitation, the electrochemical reaction at interfaces is still not elucidated. Therefore, focusing on coating/metal interfaces, this paper investigates the coating failure mechanism on the coated X80-matrix with pure DGEBA coatings and the formation process of $\mathrm{Fe}_{3} \mathrm{O}_{4}$ at interfaces.
\end{abstract}

Keywords: Epoxy coating; X80-matriax; Near-neutral; $\mathrm{Fe}_{3} \mathrm{O}_{4}$; Cathodic protection

\section{$\underline{\text { FULL TEXT }}$}

(C) 2021 The Authors. Published by ESG (www.electrochemsci.org). This article is an open access article distributed under the terms and conditions of the Creative Commons Attribution license (http://creativecommons.org/licenses/by/4.0/). 